\title{
Obtenção e caracterização de cinza de ossos bovinos visando à fabricação de porcelana de ossos - bone china
}

\section{(Preparation and characterization of bovine bone ash for the fabrication of bone china)}

\author{
R. Y. Miyahara, D. Gouvêa, S. M. Toffoli \\ Departamento de Engenharia Metalúrgica e de Materiais, Escola Politécnica da Universidade de S. Paulo \\ Av. Prof. Mello Moraes 2463. S. Paulo, SP 05508-900 \\ dgouvea@usp.br
}

\begin{abstract}
Resumo
A porcelana de ossos - bone china - é uma cerâmica de corpo especial de grande dureza e translucidez exclusivamente fabricada na Inglaterra e em outras poucas partes do mundo, mas não no Brasil. Suas matérias-primas são compostas por aproximadamente metade de cinza de ossos, além de caulim e feldspato. O trabalho apresenta a obtenção e caracterização de cinza de ossos a partir de ossos bovinos com o objetivo da fabricação de porcelanas. No processo de preparação da cinza de ossos envolve o uso de autoclave, descarnagem manual, calcinação e moagem dos ossos. As condições de preparação foram estudadas em função das condições de calcinação, moagem e lavagem do osso. A calcinação foi estudada através de análises térmicas e difração de raios X de diferentes partes do animal. O pó obtido foi caracterizado por análises químicas, medida de granulometria por difração de laser, e microscopia eletrônica de varredura. Os resultados mostraram que a matéria-prima obtida neste trabalho possui propriedades similares das originalmente utilizadas nas indústrias inglesas com baixo teor de ferro e partículas coloidais e que podem ser calcinadas a temperaturas inferiores a $1000^{\circ} \mathrm{C}$.
\end{abstract}

Palavras-chave: cinza de ossos, porcelana de ossos, bone china, caracterização do pó.

Abstract

\begin{abstract}
Bone china is a special kind of porcelain, very hard and translucent, nowadays manufactured almost exclusively in England and in few other parts of the world, but not in Brazil. Its raw-materials comprise about fifty percent of bone ash, together with kaolin and a feldspar mineral. This paper presents the preparation and the characterization of bone ash obtained from bovine bones, with the objective of obtaining bone china. The preparation of the bone ash involves the use of an autoclave, manual removal of the meat, firing, and milling the bones. The preparation conditions were studied as a function of the firing conditions, milling, and washing the powder bones. The firing step was studied by thermal analyses TG-DTA and X-ray diffraction, whereas the obtained powder was characterized in terms of its chemical composition (X-ray fluorescence), particle size distribution (laser diffraction), and scanning electron microscopy. The results indicate that the obtained raw-material exhibits similar properties to the ones of the bone ash used by the English industry, with low iron content and colloidal particles when calcined at temperatures lower than $1000{ }^{\circ} \mathrm{C}$.
\end{abstract}

Keywords: bone china, bone ash, powder characterization.

\section{INTRODUÇÃO}

As porcelanas são corpos cerâmicos densos, resistentes, de grande alvura e translucidez. Compreendem um dos mais complexos sistemas cerâmicos, tanto do ponto de vista da composição das matérias-primas como de alguns aspectos do processo de fabricação. Dentre os diferentes tipos, a porcelana de cinza de ossos (em inglês, bone china) é um tipo especial, com uma mistura de matérias-primas composta por aproximadamente $50 \%$ de cinza de ossos bovinos e também feldspatos, caulim ou outras argilas e sílica $[1,2]$. $\mathrm{Na}$ Inglaterra, em substituição ao feldspato, esse tipo de produto foi originalmente fabricado com cornish stone [3], matéria-prima originária da região de Cornwal, sudoeste do país, que é composta principalmente por minerais do grupo dos feldspatos, mas também pequenos teores de quartzo.

As características particulares da porcelana de ossos são a grande alvura e translucidez, baixa vitrificação, qualidade da decoração e também elevada resistência mecânica, que pode chegar a ser até duas vezes maior do que a das porcelanas de argilas. Essa combinação positiva de propriedades resulta em uma porcelana de mesa das mais atrativas e caras do mundo.

A proporção de fase amorfa na porcelana de ossos é de apenas $30 \%$ (diferente da porcelana convencional que contém cerca de $70 \%$ ) e a fase cristalina é formada por cristais de anortita que apresenta um índice de refração muito próximo da fase vítrea, o que garante a translucidez 
[3]. Esta característica explica o fato da porcelana de ossos apresentar uma elevada resistência ao lascamento, que pode ser até quatro vezes maior quando comparada à porcelana dura convencional, e também módulos de resistência à ruptura e ao impacto chegando a ser duas vezes maiores [4]. A cinza de ossos é a única matéria-prima utilizada em grande quantidade na fabricação de cerâmicas que não é originária do solo e também renovável. Contudo, poucos trabalhos são conhecidos sobre as propriedades de ossos bovinos calcinados $[5,6]$. É usualmente obtida por calcinação de ossos de animais em temperaturas que variam de 900 a $1000{ }^{\circ} \mathrm{C}$ [3], e posteriormente sofre um processo de cominuição e lavagem. A moagem dos agregados de cristais obtidos após calcinação resulta em um material bastante fino. Entretanto, cinzas de ossos não são inertes quando suspensas em água. Durante um estágio de envelhecimento de uma suspensão de cinza de ossos em água, trocas iônicas e solubilização de íons são possíveis, o que pode prejudicar o comportamento reológico da dispersão.

O Brasil possui uma indústria de porcelana bem estabelecida e uma vasta e renovável disponibilidade de ossos animais, principalmente provenientes de bovinos. Contudo, não se conhecem relatos sobre indústrias de grande, médio ou pequeno portes produzindo porcelana de ossos. Tampouco a literatura técnica nacional apresenta trabalhos tecnológicos ou pesquisas que abordem ou discutam a fabricação desse tipo de porcelana. Recentemente foi publicado trabalho sobre o assunto nesta revista, contudo as informações apresentadas tiveram mais um caráter de revisão da bibliografia que divulgação de novos resultados [7].

Ossos são constituídos predominantemente por hidroxiapatita que na mistura da porcelana de ossos se decompõe sob ação do calor em $\beta$-fosfato tricálcico (TCP), $\mathrm{CaO}$ e água. A reação de decomposição inicia a temperaturas superiores a $775^{\circ} \mathrm{C}[8]$, de acordo com a seguinte reação:

$$
\mathrm{Ca}_{10}\left(\mathrm{PO}_{4}\right)_{6}(\mathrm{OH})_{2} \rightarrow 3 \mathrm{Ca}_{3}\left(\mathrm{PO}_{4}\right)_{2}+\mathrm{CaO}+\mathrm{H}_{2} \mathrm{O}
$$

Outros autores pesquisaram o uso de matériasprimas alternativas para a fabricação de porcelanas com a substituição da cinza de ossos por outras matériasprimas, tais como rochas fosfáticas [9-11]. Estas, quando calcinadas, produzem fosfato tricálcico, que tem a composição química e cristalográfica semelhantes e que podem ser adequadas para a fabricação de porcelana. Entretanto, experimentos usando este material não têm sido completamente bem sucedidos, uma vez que nessas rochas freqüentemente existem pequenos teores de cromo, o que pode resultar em problemas de coloração como o escurecimento.

A despeito da porcelana de ossos ser um produto fabricado há bastante tempo e diversos de seus aspectos de fabricação e propriedades finais já terem sido estudados, os fenômenos e as reações responsáveis pela formação de suas fases durante a queima e a formação da microestrutura, bem como a preparação das matérias-primas, ainda é pouco compreendida.
O objetivo deste trabalho foi estudar a preparação da cinza de ossos bovinos para seu posterior uso na fabricação de porcelanas. As principais etapas de processo estudadas foram: a decomposição térmica, a moagem e a lavagem. Para isso foram realizadas análises de distribuição granulométrica por espalhamento de laser, análise química por fluorescência de raios X, análise de fases por difração de raios X, análises térmicas e observação da cinza de ossos em microscópio eletrônico de varredura.

\section{EXPERIMENTAL}

A produção da cinza de ossos envolve a lavagem em autoclave dos ossos para eliminação de tecidos animais agregados e subseqüentes separação dos componentes orgânicos, principalmente o excesso de gordura e sangue. Esta operação foi realizada, tratando-se os ossos bovinos em autoclave de laboratório (Fabbe Primar Industrial Ltda, modelo 103), por $1 \mathrm{~h}$ à pressão de $1 \mathrm{~atm}$ e em seguida a eliminação manual de possíveis tecidos musculares ainda agregados aos ossos.

Mesmo após lavagem, os ossos bovinos ainda contêm resíduo de gordura. Além disto, reações de decomposição da hidroxiapatita são esperadas quando o material for submetido ao tratamento térmico. Assim, com o objetivo de acompanhar as transformações térmicas do osso foram realizadas análises térmicas com o material após autoclave e seco a $100{ }^{\circ} \mathrm{C}$. As análises termogravimétricas, TG, e análise térmica diferencial, ATD, foram executadas até a temperatura de $1200^{\circ} \mathrm{C}$ com taxa de aquecimento de $20^{\circ} \mathrm{C} /$ min em atmosfera de ar sintético em um equipamento TA, modelo SDT Q600.

Para verificação da evolução das fases cristalinas, os ossos foram calcinados em forno elétrico tipo mufla (Quimis) nas temperaturas de $500,700,900,1000,1100$ e $1200^{\circ} \mathrm{C}$, utilizandose taxa de aquecimento de $10^{\circ} \mathrm{C} / \mathrm{min}$ com tratamento por $1 \mathrm{~h}$. Com os produtos das calcinações foram executadas análises de difração de raios X (DRX), desde o material autoclavado e seco a $100^{\circ} \mathrm{C}$ até a temperatura de $1200^{\circ} \mathrm{C}$, em equipamento Philips X'PERT MPD, utilizando a radiação K $\alpha$ do cobre, na rotina $\theta / 2 \theta$ de $2-90^{\circ}$, com passos de $0,02^{\circ}$ e tempo de permanência de $1 \mathrm{~s}$.

Após lavagem e calcinação, a cinza de ossos foi moída utilizando jarros de porcelana e esferas de alta alumina como elementos de moagem. A medida da distribuição granulométrica foi realizada por dispersão de laser utilizando equipamento Malvern Mastersizer-E. A área de superfície específica (ASE) foi determinada pelo método BET pela adsorção de $\mathrm{N}_{2}$ para o material calcinado a $1000{ }^{\circ} \mathrm{C}$ após moagem utilizando-se um instrumento Micromeritics ASAP2010.

Os ossos são fontes de cálcio e fósforo. Entretanto, apresentam pequenas quantidades de outros íons em sua composição, como sódio e potássio e, dependendo da lavagem, Fe proveniente do sangue. Os sais solúveis modificam o comportamento reológico de barbotinas, além de mudarem seu comportamento durante a sinterização 
devido à ação fundente. $\mathrm{O}$ ferro pode modificar a cor do material. Para verificar a remoção dos sais foram feitas lavagens desse material com água destilada utilizando uma relação de $100 \mathrm{~g}$ de cinza de ossos para $2 \mathrm{~L}$ de água, com $1 \mathrm{~h}$ de agitação repetida 3 vezes. Para avaliar o efeito da lavagem das cinzas calcinadas a diferentes temperaturas na composição química das cinzas, foram realizadas análises de composição antes e após a lavagem do pó pela técnica de fluorescência de raios X.

Para avaliar a forma das partículas da matéria-prima obtida nesse trabalho foi realizada microscopia eletrônica de varredura (MEV) utilizando um Microscópio Eletrônico de Varredura Philips XL-30, com filamento de tungstênio, tensão de aceleração de 20 kV.

\section{RESULTADOS E DISCUSSÃO}

\section{Decomposição térmica dos ossos}

Para verificar as etapas da decomposição do osso durante o tratamento térmico foram realizados ensaios de análise térmica e os resultados encontram-se na Fig. 1. As curvas indicam que a partir de $100{ }^{\circ} \mathrm{C}$ inicia-se a diminuição da quantidade de massa do material. Isto ocorre devido à perda de água na forma de vapor. A evaporação da água é uma reação endotérmica, mostrada pela curva de ATD. Em aproximadamente $300{ }^{\circ} \mathrm{C}$ inicia-se uma segunda reação exotérmica que se prolonga até aproximadamente $700{ }^{\circ} \mathrm{C}$ onde é observada uma queda acentuada da massa e que deve estar provavelmente relacionada à reação de combustão da matéria orgânica contida nos ossos bovinos. Quando o material é calcinado a $450{ }^{\circ} \mathrm{C}$, temperatura em que a matéria orgânica é pirolisada, ocorre a formação de uma camada de carvão nos ossos que é eliminada a temperaturas superiores. As curvas indicam ainda que ocorre perda de massa até a temperatura de aproximadamente $1200{ }^{\circ} \mathrm{C}$, porém, numa taxa menor. Estudos termogravimétricos da hidroxiapatita [13] demonstraram que durante o aquecimento ocorrem

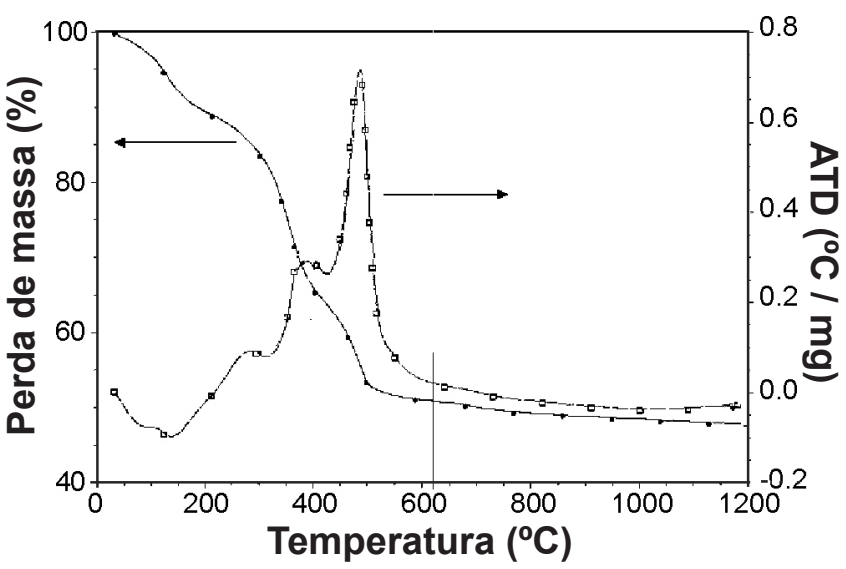

Figura 1: Curvas de TG e ATD do osso in natura com taxa de aquecimento de $20^{\circ} \mathrm{C} / \mathrm{min}$ com atmosfera de ar sintético.

[Figure 1: TG and DTA curves of natural bone (temperature rate of $20^{\circ} \mathrm{C} / \mathrm{min}$ and natural air atmosphere.] duas reações principais: uma de dessorção de água e a outra de desidroxilação [5]. Essas reações podem explicar a perda de massa contínua observada até temperaturas elevadas $\left(1200{ }^{\circ} \mathrm{C}\right)$. Os resultados de análise térmica determinaram que as temperaturas de preparação do pó deveriam corresponder ao final das reações de combustão, ou seja, acima de $700{ }^{\circ} \mathrm{C}$.

As curvas de difração de raios $\mathrm{X}$ da cinza de ossos calcinada a diferentes temperaturas apresentadas na Fig. 2 mostram que, após calcinação, a estrutura da fase cristalina é da hidroxiapatita (HA). Esta observação está de acordo com a literatura [3,11-13]. A temperatura de $700{ }^{\circ} \mathrm{C}$ parece ser suficiente para se obter HA para utilização na fabricação de porcelanas de osso, temperatura inferior àquela apresentada na literatura $[3$, 12], onde se indica que a temperatura de calcinação dos ossos deve ser de pelo menos $1000^{\circ} \mathrm{C}$. Existem algumas justificativas apresentadas na literatura, como o tamanho final das partículas, para a calcinação em temperaturas de $1000{ }^{\circ} \mathrm{C}$, contudo esta possibilidade está sendo investigada com maiores detalhes e serão apresentadas em trabalho futuro.

Ainda na Fig. 2 pode-se observar que para a temperatura de $500{ }^{\circ} \mathrm{C}$ o difratograma é atenuado quando comparada com os difratograma de outras temperaturas. Como esta é a temperatura onde ocorre a queima da matéria orgânica observada na análise térmica - Fig. 1, parte dos produtos de decomposição da matéria orgânica deve permanecer aderida à superfície do material na forma de material carbonizado gerando uma cor negra, a qual vai ser gradativamente eliminada à medida que a temperatura se eleva. Esta camada de material carbonizado atenua a resposta aos raios $\mathrm{X}$, diminuindo, desse modo, a intensidade dos picos da fase cristalina. Este resíduo é detectado visualmente, pois o material calcinado a essa temperatura apresenta coloração negra. Temperaturas superiores a $500{ }^{\circ} \mathrm{C}$ são suficientes para completar a queima do carbono residual ao mesmo tempo em que o material torna-se branco e os picos dos difratogramas tornam-se mais intensos. Do ponto de vista de mudanças da composição com a temperatura, há indicações na literatura $[3,12,13]$ de que na obtenção da hidroxiapatita a partir de ossos bovinos ocorre com a formação de $\mathrm{CaO}$. Contudo, as análises de DRX indicam somente a presença de hidroxiapatita e nenhuma presença de fase cristalina do $\mathrm{CaO}$ foi observada nas temperaturas de calcinação utilizadas. A liberação do $\mathrm{CaO}$ constatadas em trabalhos anteriores pode ter ocorrido na presença das outras matérias-primas, reagindo com a cinza de ossos e formando, durante a etapa de queima do processo de fabricação, outras fases cristalinas além de TCP, tal como a anortita de composição $\left(\mathrm{CaO} \cdot \mathrm{Al}_{2} \mathrm{O}_{3} \cdot 2 \mathrm{SiO}_{2}\right)$.

Após a calcinação, algumas partes apresentavam certa tonalidade de cor que variaram entre o branco, o preto e o vermelho. Contudo as variações parecem não estar ligadas às possíveis diferenças de fase cristalina do material nem à composição química como pode ser visto na Fig. 3 . 


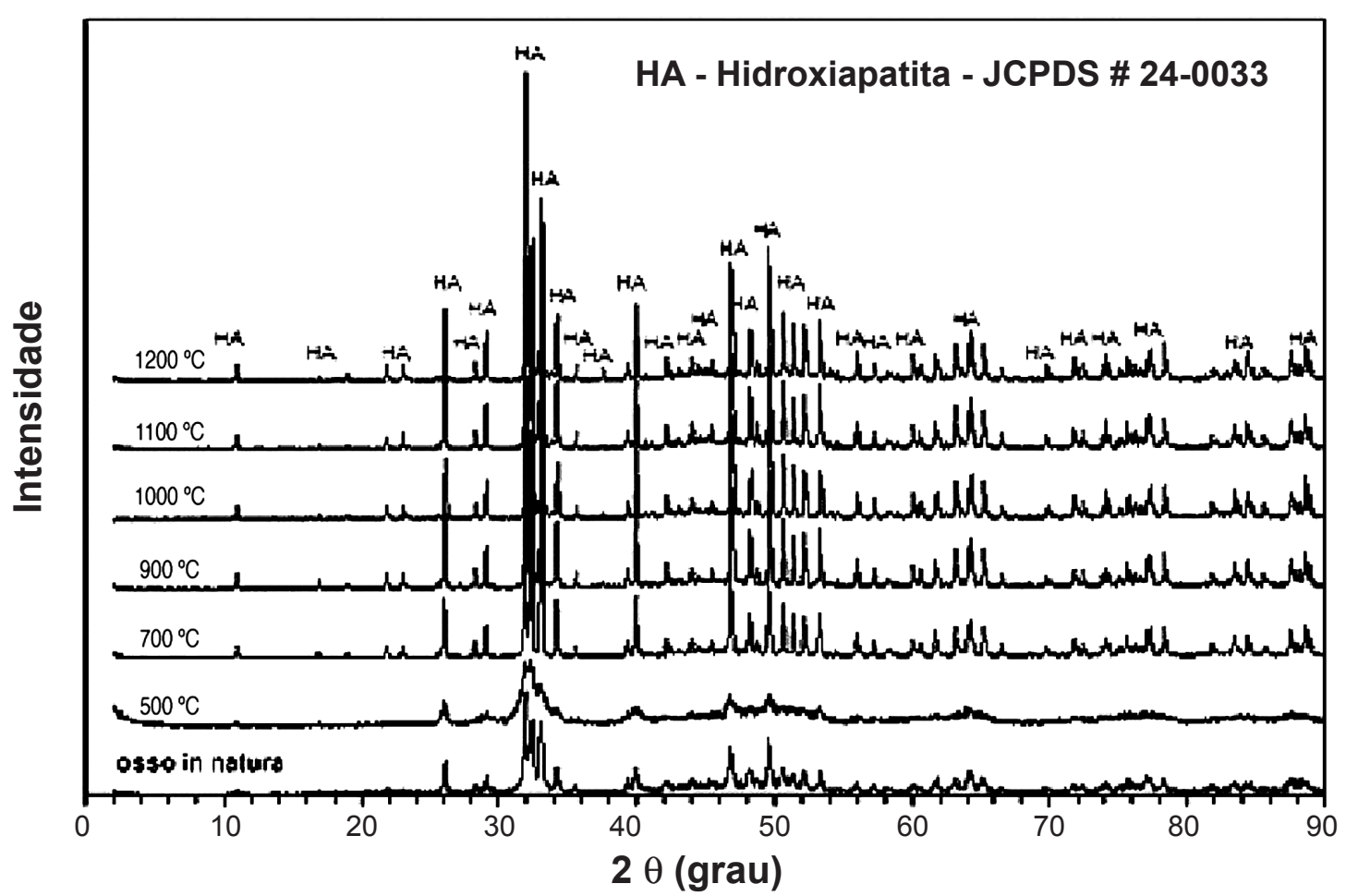

Figura 2: Difração de raios X do osso in natura e calcinado em diferentes temperaturas. [Figure 2: XRD of the natural bone and calcined bone at different temperatures.]

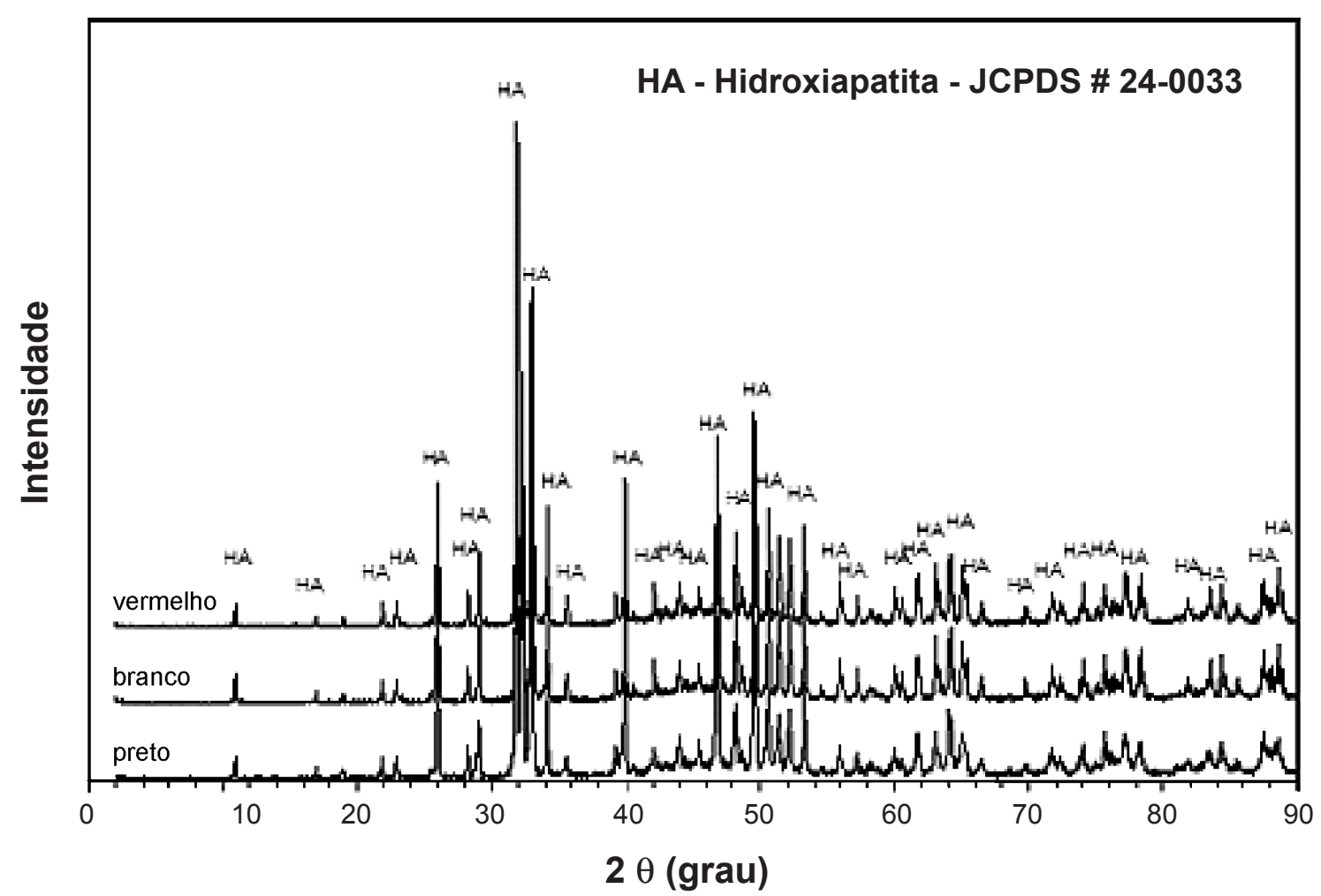

Figura 3: Difração de raios X de ossos calcinados a $1000{ }^{\circ} \mathrm{C}$ com diferentes tonalidades de cor após calcinação. [Figure 3: XRD patterns of the different color bones after calcination at $1000^{\circ} \mathrm{C}$.] 


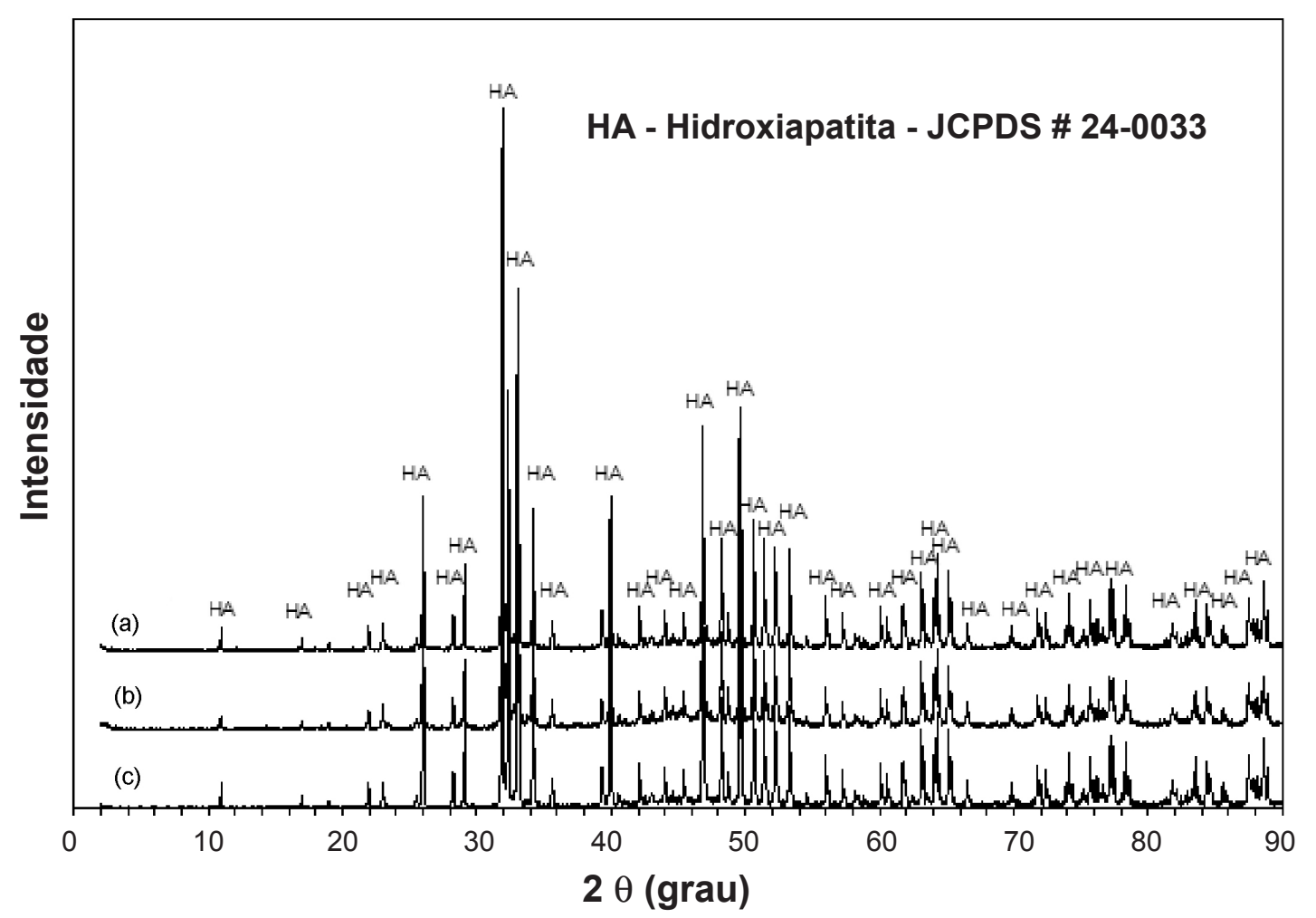

Figura 4: Difração de raios X de ossos calcinados a $1000{ }^{\circ} \mathrm{C}$ de diferentes partes do esqueleto bovino (a) perna parte superior, (b) costelas e (c) perna parte inferior.

[Figure 4: XRD patterns of the bones from different parts of the bovine after calcination at $1000^{\circ} \mathrm{C}$. (a) higher leg, (b) rib and (c) lower leg.]

Outro ponto relevante a ser apontado é o fato de que não há diferenças significativas na composição de fases cristalinas do osso calcinado preparado a partir de diferentes partes do animal, como pode ser visto nas curvas de DRX da Fig. 4.

\section{Características do pó de cinza de ossos}

As análises químicas antes e após lavagem do pó de cinzas de ossos calcinado a $1000{ }^{\circ} \mathrm{C}$ foram realizadas por fluorescência de raios X e são apresentadas na Tabela I. Os resultados mostram que a composição química dos materiais obtidos é muito próxima antes e depois do processo de lavagem com exceção do valor do $\mathrm{Na}_{2} \mathrm{O}$ que diminuiu de 1,11 para $0,74 \%$ com a lavagem. Contudo, para a amostra lavada foram detectados $\mathrm{Al}_{2} \mathrm{O}_{3}$ e $\mathrm{SiO}_{2}$. Aparentemente a contaminação ocorreu devido ao processo de moagem no qual foi utilizado jarro de porcelana com esferas de alta alumina. Estes contaminantes não são problemáticos, já que fazem parte da composição química da porcelana. A presença de óxido de ferro não foi verificada nas análises, contrariamente ao apresentado na literatura [7]. A diferença pode vir do procedimento da lavagem dos ossos e da remoção dos resíduos. A lavagem
Tabela I - Análise química semiquantitativa por fluorescência de raios $\mathrm{X}$ da cinza de ossos calcinados a $1000{ }^{\circ} \mathrm{C}$ e após lavagem.

[Table I - Semi-quantitative chemical analysis by X-ray fluorescence of bone calcined at $1000{ }^{\circ} \mathrm{C}$ with and without wash.]

\begin{tabular}{ccc}
\hline óxido & Calcinado & Calcinado e lavado \\
\hline $\mathrm{CaO}$ & 55,6 & 55,0 \\
$\mathrm{P}_{2} \mathrm{O}_{5}$ & 41,7 & 42,6 \\
$\mathrm{SiO}_{2}$ & $\mathrm{ND}$ & 0,02 \\
$\mathrm{Al}_{2} \mathrm{O}_{3}$ & $\mathrm{ND}$ & 0,21 \\
$\mathrm{Na}_{2} \mathrm{O}$ & 1,11 & 0,74 \\
$\mathrm{~K}_{2} \mathrm{O}$ & 0,02 & $\mathrm{ND}$ \\
$\mathrm{MgO}$ & 1,13 & 1,12 \\
$\mathrm{BaO}$ & 0,10 & $\mathrm{ND}$ \\
$\mathrm{ZnO}$ & 0,02 & 0,02 \\
$\mathrm{SrO}$ & 0,07 & 0,06 \\
$\mathrm{Cl}$ & 0,06 & 0,06 \\
$\mathrm{Fe}_{2} \mathrm{O}_{3}$ & $\mathrm{ND}$ & $\mathrm{ND}$ \\
$\mathrm{SO}$ & 0,18 & 0,18 \\
$\mathrm{Total}_{3}$ & 100 & 100 \\
\hline
\end{tabular}

$\mathrm{ND}=$ não detectado 


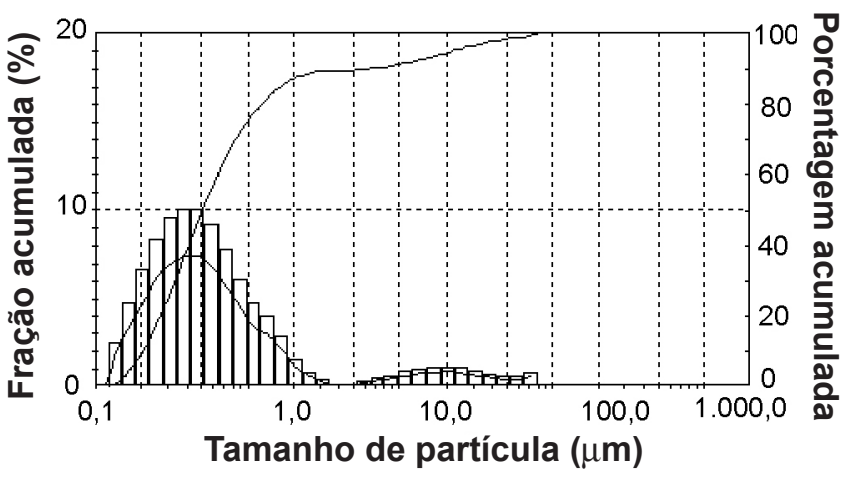

Figura 5: Distribuição granulométrica da cinza de ossos após calcinação a $1000^{\circ} \mathrm{C}$ e moagem.

[Figure 5: Particle size distribution of calcined bone after calcination at $1000^{\circ} \mathrm{C}$ and milling.]

em autoclave permite uma remoção muito eficiente dos resíduos de sangue e da carne e conduz a obtenção de um material livre de óxido de ferro que pode interferir na cor final do produto.

A distribuição granulométrica da cinza de ossos após calcinação e moagem é mostrada na Fig. 5. Verificouse que 45 min de moagem é suficiente para se obter um material com praticamente $90 \%$ em tamanho coloidal. A medida da área superficial específica (ASE) pelo método BET deste mesmo material foi de $2,56 \mathrm{~m}^{2} / \mathrm{g}$. Considerando que a densidade do osso calcinado é cerca de $2,5 \mathrm{~g} / \mathrm{cm}^{3}$, temse um tamanho médio de partículas de $0,9 \mu \mathrm{m}$ que é coerente com os resultados apresentados de granulometria.

$\mathrm{Na}$ micrografia obtida por microscopia eletrônica de varredura, Fig. 6, pode-se observar a morfologia das partículas de cinza de ossos e o tamanho médio. O produto da moagem apresenta grãos de formatos equiaxiais de tamanho muito pequeno confirmando as medidas de distribuição granulométrica e de ASE.

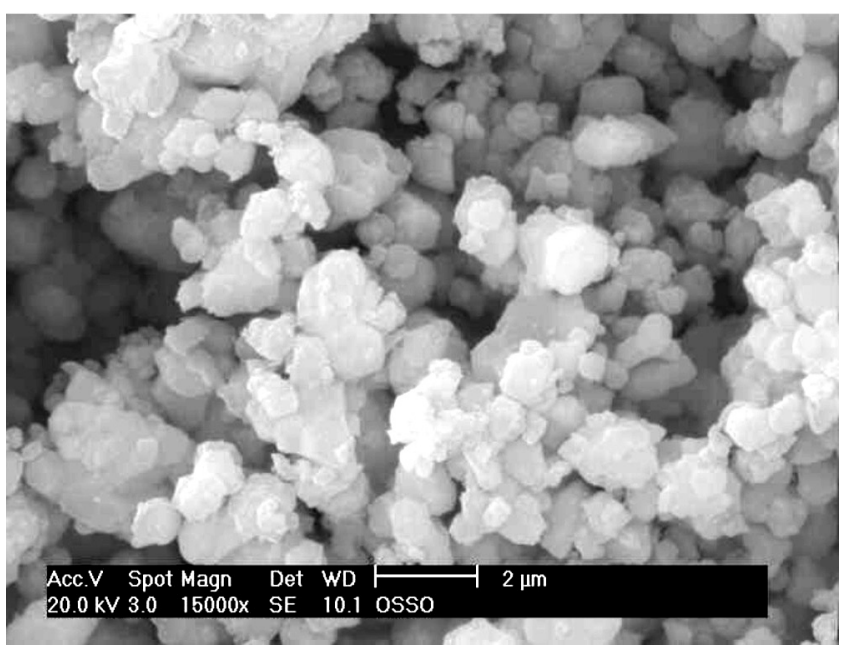

Figura 6: Micrografia eletrônica de varredura das partículas de cinza de ossos calcinadas a $1000{ }^{\circ} \mathrm{C}$.

[Figure 6: SEM of the bone particles after calcination at $1000^{\circ} \mathrm{C}$ and milling.]

\section{CONCLUSÕES}

Cinza de ossos foram obtidos através da lavagem em autoclave, calcinação e moagem de ossos bovinos. A análise térmica mostra que o material pode ser obtido a temperaturas superiores a $700^{\circ} \mathrm{C}$. Os pós de cinza de ossos calcinados a $1000{ }^{\circ} \mathrm{C}$ e moídos durante $45 \mathrm{~min}$ em moinho de porcelana apresentam uma distribuição granulométrica com partículas coloidais e área de superfície específica de $1,27 \mathrm{~m}^{2} / \mathrm{g}$. A composição química variou pouco com a lavagem da cinza de ossos e íons cromóforos, como o Fe, não foram detectados. Contudo, foi verificada a contaminação com $\mathrm{Al}_{2} \mathrm{O}_{3}$ e $\mathrm{SiO}_{2}$ devido aos elementos de moagem, mas que não comprometem a utilização da cinza de ossos para a fabricação de porcelana já que estes óxidos fazem parte da composição química da porcelana. Diferentes partes do esqueleto do animal foram utilizadas para a preparação da cinza de ossos, mas nenhuma diferença significativa foi observada nas fases formadas. A microscopia eletrônica de varredura mostrou partículas equiaxiais com tamanhos inferiores a $1 \mu \mathrm{m}$. O conjunto dos resultados demonstra a viabilidade da preparação da cinza de ossos a partir de bovinos para a fabricação de bone china.

\section{AGRADECIMENTOS}

O apoio financeiro da FAPESP (Proc. 03/12721-2), do CNPq (Proc. 475029/2003-8) e à CAPES pela bolsa de doutoramento.

\section{REFERÊNCIAS}

[1] F. H. Norton, Introdução à Tecnologia Cerâmica, 2a Ed., Ed. Edgard Blucher, S. Paulo, Brasil (1984).

[2] Dinsdale, Pottery Science Material, Process \& Products, John Wiley \& Sons, Chichester, UK (1986).

[3] P. Rado, An Introduction to the Technology of Pottery, $2^{\text {nd }}$ Ed., The Institute of Ceramics, Pergamon Press, Oxford (1988).

[4] S. A. F. Batista, P. F. Messer, R. J. Hand, Fracture toughness of bone china and hard porcelain, Ceram. Trans. J. 100, 6 (2001) 256.

[5] D. Basnett, P. J. Cartwirght, The effect of bone properties on china casting, Brit. Ceram. Trans. J. 88, 5 (1989) 191.

[6] J. J. Cooper, Bone for bone china, Brit. Ceram. Trans. J. 94, 4 (1995) 165

[7] S. R. Bragança, C. P. Bergmann, Produção de porcelana de ossos e caracterização de suas propriedades, Cerâmica 52 (2006) 205.

[8] K. Tsuyoshi, J. Ceram. Soc. Jap. 107 (1999) 476.

[9] A. J. Forrester, Brit. Ceram. Trans. J. 85, 6 (1986) 180. [10] D. Taylor, K. K. Nijhawan, W. Norris, Brit. Ceram. Trans. J. 78, 5 (1979) 108

[11] C. E. L. Franklin, A. J. Forrester, Brit. Ceram. Trans. J. 74 (1975) 141.

(Rec. 12/09/2006, Ac. 09/02/2007) 